\title{
Effect of Adverse Weather Conditions on Vehicle Braking Distance of Highways
}

\author{
Ali Abdi Kordani ${ }^{\text {a }}$, Omid Rahmani ${ }^{\text {b* }}$, Amir Saman Abdollahzadeh Nasiri ${ }^{\mathrm{c}}$, Sid \\ Mohammad Boroomandrad ${ }^{\mathrm{d}}$ \\ ${ }^{a}$ Assistant Professor, Department of Civil Engineering, Imam Khomeini International University, Qazvin, Iran. \\ ${ }^{b}$ Lecturer, Department of Civil Engineering, Roudehen Branch, Islamic Azad University, Tehran ,Iran.
}

${ }^{c}$ Master of science Student, Department of Civil Engineering- Highway and Transportation Engineering, South Tehran Branch, Islamic Azad University, Tehran, Iran.

${ }^{d}$ Master of science Student, Department of Civil Engineering-Highway and Transportation Engineering, Science and Research branch, Islamic Azad University, Tehran, Iran.

Received 23 November 2017; Accepted 20 January 2018

\begin{abstract}
The effect of adverse weather conditions on the safety of vehicles moving on different types of roads and measuring its margin of safety have always been a major research issue of highways. Determining the exact value of friction coefficient between the wheels of the vehicle and the surface of the pavement (usually Asphalt Concrete) in different weather conditions is assumed as a major factor in design process. An appropriate method is analyzing the dynamic motion of the vehicle and its interactions with geometrical elements of road using dynamic simulation of vehicles. In this paper the effect of changes of friction coefficient caused by the weather conditions on the dynamic responses of three types of vehicles: including Sedan, Bus, and Truck based on the results of Adams/car Simulator are investigated. The studies conducted on this issue for different weather conditions suggest values ranging from 0.04 to 1.25 . The results obtained from simulation based on Adams/car represent that the friction coefficient in values of 0.9, 0.8, 0.7, 0.6 do not effect on braking distance significantly and it is possible to attribute them all to dry weather condition. However, as it was anticipated the values of $0.5,0.4,0.28$ and 0.18 have significant differences in braking distance. Hence, the values of $0.5,0.4,0.28$ and 0.18 can be attributed to wet, rainy, snowy and icy conditions respectively.
\end{abstract}

Keywords: Road Conditions; Friction Coefficient; Dynamic Responses of the Vehicle; Braking Distance; Simulation.

\section{Introduction}

The effect of undesirable road conditions on the safety of current vehicles on different types of roads is constantly considered as a major subject in Transportation engineering in all over the world. The statistics of fatality represent that winter, as the most adverse weather condition, not only can it have significant effect on road surface, but also is considered as a major factor particularly where transportation and weather condition are interconnected, this means, Geometric Design and Road Safety, Figures 1 and 2 show the number of fatality of accidents in the US between 2009 and 2010 clearly [1].

The role of Geometric Design, by defining the exact value of the friction coefficient between the surface of the road (usually Asphalt Concrete) and the tire of vehicle which occurs in different weather conditions as major factor, on the other hand the dynamic response of the vehicle as a second factor, have to be investigated. When the parameters of Geometric design and vehicles are investigated interactively, it could be said that designing is close to reality.

\footnotetext{
* Corresponding author: its4kar@yahoo.com
} 
In this paper, according to neglect the effect of weather conditions on the road surface and consequently the change in the interaction between the vehicle and the road and effect of the type of vehicle (weight, dynamic conditions), the codes valid geometric design, to simulate and present a model for estimating the effect of the mentioned factors on braking distance. In this paper, in order to investigate the interaction between road and vehicle on each other precisely, Adams/car is used.

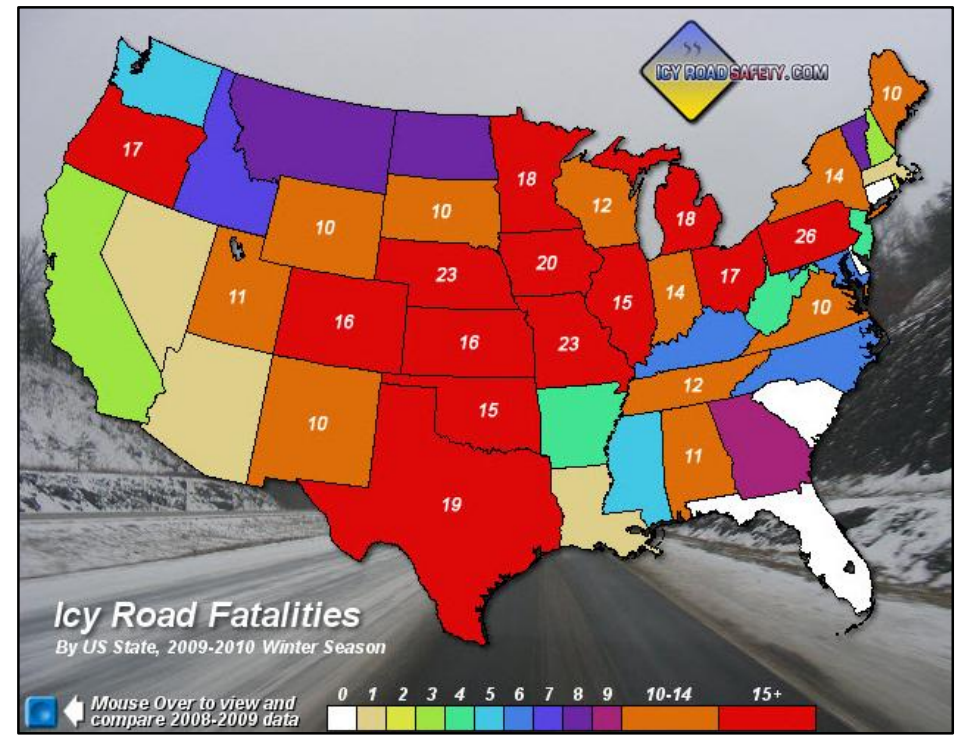

Figure 1. Number killed of roads in various states of America in freezing conditions during the years 2009-2010 [1]

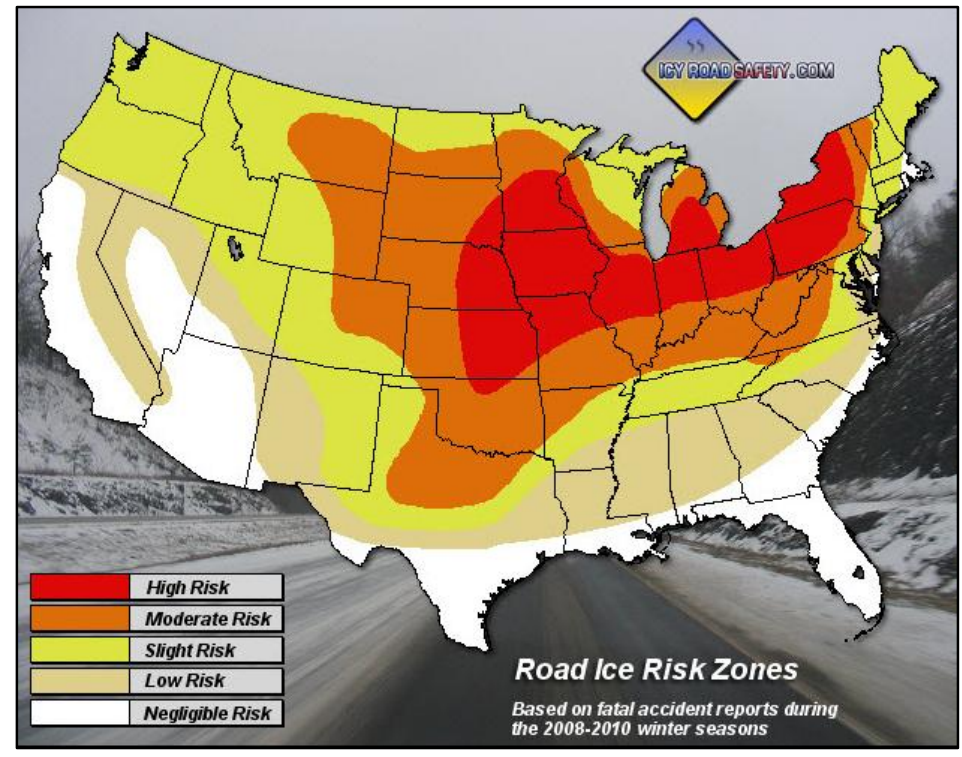

Figure 2. Zones with the possibility of creating frosts on the road (in winter), The United States of America [1]

\subsection{Weather Effects on Safety}

There are over 5,760,000 vehicle crashes annually. Roughly $22 \%$ of which are related to weather, almost 1,259,000 (1,258,978 crashes). These crashes are recognized as those taking place in adverse weather (i.e., blowing snow/sand/debris or rain, sleet, snow, fog, severe crosswinds) or even on slick pavement (i.e., , snowy/slushy pavement, icy pavement, or wet pavement). On average, approximately 6,000 (5,879 fatalities) are killed and over 445,000 (445,303 people injured) are injured in weather-related crashes annually (Figure 3). (Source: Ten-year averages from 2004 to 2014 analyzed by Booz Allen Hamilton, based on NHTSA data). The majority of most weather-related crashes take place on wet pavement while rainfall: $73 \%$ on wet pavement and $46 \%$ during rainfall. A very smaller percentage of weather-related crashes take place in winter conditions: $17 \%$ while snowing or sleet, $13 \%$ take place in icy pavement and $14 \%$ of them occur on snowy or slushy pavement. Not more than $3 \%$ occur in foggy weather. (Source: Ten-year averages from 2004 to 2014 analyzed by Booz Allen Hamilton, based on NHTSA data)[2]. 


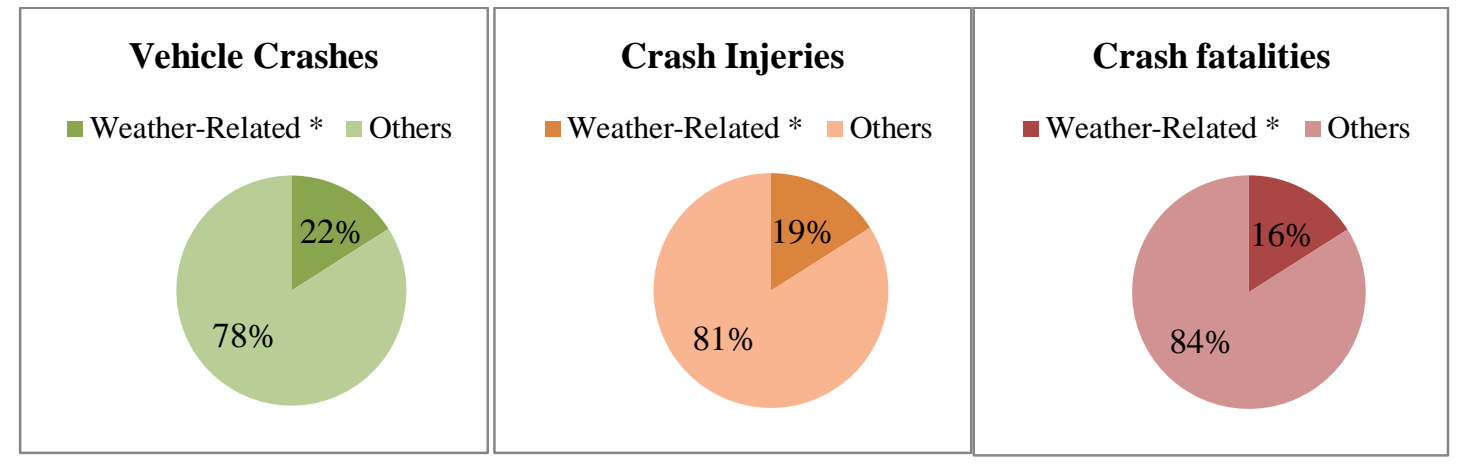

Note: "Weather-Related" crashes are those that occur in the presence of adverse weather and/or slick pavement conditions

Figure 3. Weather-Related Crash Statistics (10-year Percentages) NHTSA data

It can be seen in Figure 4, segregated, accident statistics (damage, injury and death) in a variety of road weather conditions:

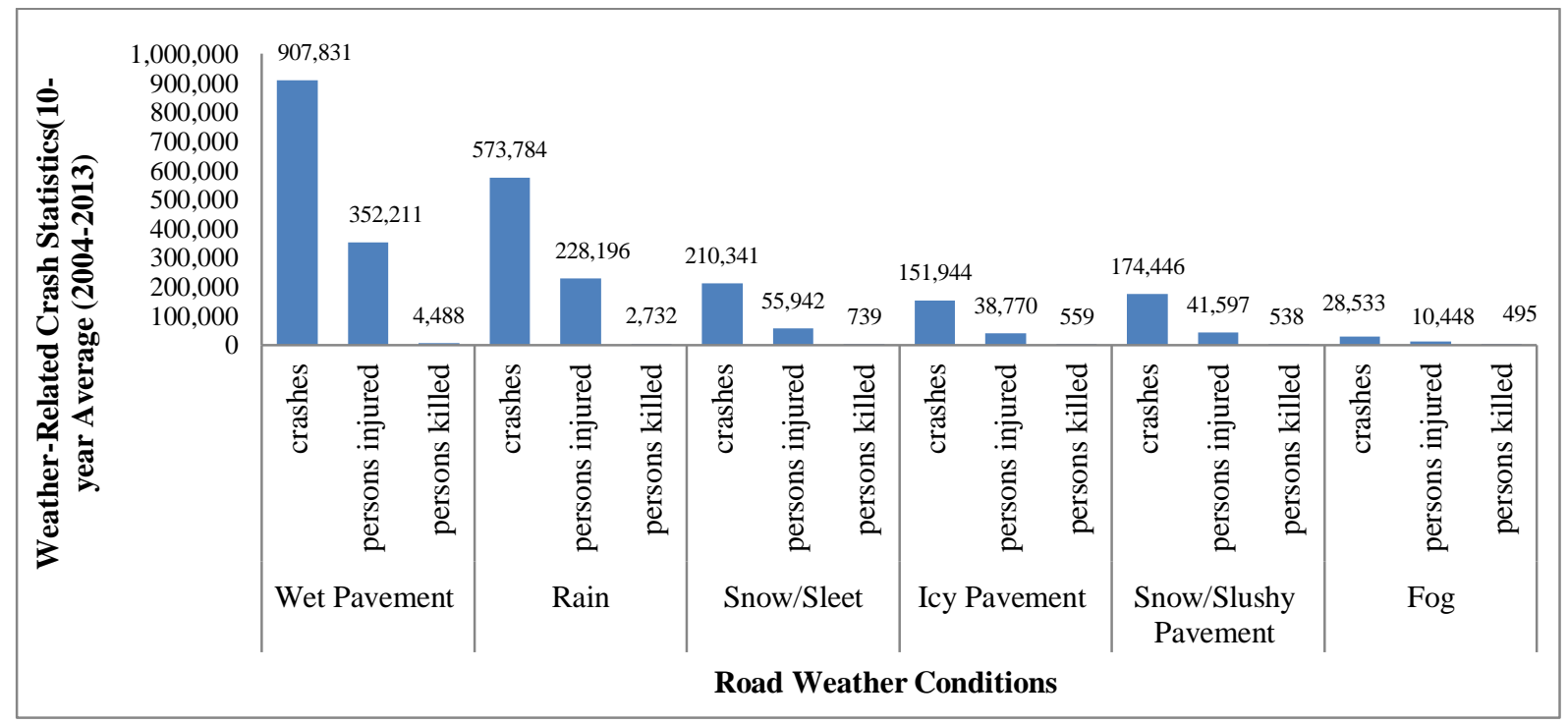

Figure 4. Weather-Related Crash Statistics (Annual Averages) 10-year Average (2005-2014) NHTSA data [2]

AASHTO the Green Book regulations, focuses more on the road surface which attributes the wet condition as the worst friction coefficient (Current AASHTO: Green Book 2011, Previous AASHTO: book 1994) (See Table 1) this is while many vehicles and their drivers experience the icy and snowy road conditions. Obviously, the weather condition such as rainfall can change the road surface condition. For instance, in snowy condition surface frustration, compacted snow, soft snow, and slush can be observed which makes the investigation essential.

Table 1. Investigating on suggested values for friction coefficient in different editions of AASHTO [5]

\begin{tabular}{|c|c|c|}
\hline Description & Suggested values for the coefficient of friction & Code and year \\
\hline \multirow{9}{*}{$\begin{array}{l}\text { The whole maximum and minimum } \\
\text { suggested values are based on speed } \\
\text { parameter that the highest value is for } \\
\text { speed of } 112 \mathrm{~km} / \mathrm{h} \text {, and the lowest } \\
\text { value is for speed of } 48 \mathrm{~km} / \mathrm{h} \\
\text { (Wet Pavement and locked wheel) } \\
\text { (previous AASHTO) }\end{array}$} & $\operatorname{Max}=0.5$ & AASHTO1940 \\
\hline & $\operatorname{Min}=0.4$ & \\
\hline & Max $=0.36$ & AASHTO 1954 \\
\hline & Min=0.29 & \\
\hline & $\operatorname{Max}=0.36$ & AASHTO 1965[4] \\
\hline & Min $=0.27$ & \\
\hline & Max $=0.35$ & AASHTO 1971 \\
\hline & Min $=0.27$ & \\
\hline & Slightly higher at higher speeds than 1970 Values & AASHTO $1984 \& 1990$ \\
\hline \multirow{3}{*}{ Current AASHTO } & \multirow{3}{*}{$\begin{array}{l}\text { Suggested values in these editions of AASHTO are } \\
\text { based on speed and deceleration rather than friction } \\
\text { coefficient }\end{array}$} & AASHTO 2001 \\
\hline & & AASHTO 2004 \\
\hline & & AASHTO 2011[3] \\
\hline
\end{tabular}

Since in Geometric Design of roads Stopping Sight Distance (SSD), Passing Sight Distance (PSD) and Decision Sight Distance (DSD) are directly related to the value of friction coefficient, defining the exact value particularly in 
modes that most drivers brake while accelerating, and this study becomes more important. In this paper, the effect of motion features of heavy vehicles such as bus and truck, driver behavior while Braking which usually occurs steering free (wheels with lateral movement) or locked steering (wheels with very little lateral movement) are investigated in addition to what mentioned previously.

\section{Literature Review}

Studies run on friction are divided into three different categories:

1. The changes of surface texture and pavement materials, Geometric features and the fabric of tire on the friction coefficient.

2. Relation between Geometric Design parameters (such as radius of horizontal curves and vertical alignments, stopping sight distances the speed of vehicle, slope and Super elevation).

3. The effect of weather conditions on road surface and on friction coefficient

In studies that are divided into category 1, the values of friction are acceptable unless the road surface loses its primary state, as an example, in case of snow drop and compacted snow or ice which causes the road surface to become unusual, the same friction coefficient cannot be used. This is because porous surface is covered with compacted snow and ice and low surface roughness has low impact on the friction coefficient (for example [6]).

In studies in category 2, usually the friction coefficient is obtained by harvesting field of acceleration, speed and stopping distance of vehicles and also slope and geometric features (for example [7]).

Studies of category 3, the effect of weather conditions directly on road conditions and the value of friction coefficient is measured which is the subject of this paper as well.

In AASHTO Green Book 2011[3], the effect of weather conditions derived from designing parameters such as weight, size, the effect of center of mass and so are not considered numerically and precisely in sudden stops. The studies show that most drivers to stop suddenly while facing an unexpected object brake with the rate of deceleration greater than 4.5 meter per square seconds, and also about $90 \%$ of drivers under normal conditions brake with the deceleration rate of 3.4 meter per square seconds [5]. In order to compare and include the value of friction coefficient in different weather conditions and relate its effect on Road friction coefficient while braking, it is necessary to use a relationship for manual calculations that the value of friction coefficient is applicable. Therefore, because current AASHTO (2011) is according to the changes of suggested values of speed and acceleration, instead of using current AASHTO (2001, 2004, 2011), AASHTO (1990 and before) is used in which friction coefficient is directly based on vehicle type and physical relationships. (Gained relationship is in [4]).

As it is shown in Figure 5, there is no force toward forward and vehicle movement is gained through force interaction between friction and engine:

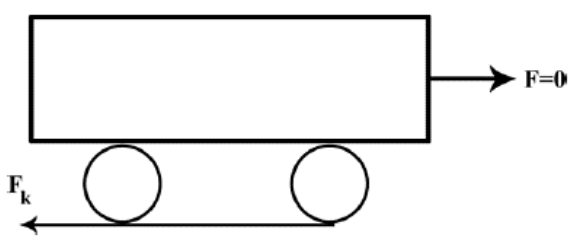

Figure 5. Forces Diagram

The force that moves the vehicle forward $=0$

$F_{k}=$ Friction coefficient $\times N=\mu \times m g$

Newton's Second Law:

$\sum F=m a \Rightarrow 0-F_{k}=m a \Rightarrow 0-\mu(m g)=m a \Rightarrow a=-\mu g$

Independent of time:

$v_{2}^{2}-v_{1}^{2}=0-v^{2}=2(-\mu g) d \Rightarrow d=\frac{v^{2}}{2 \mu g} \stackrel{\left(g=9.81 \frac{\mathrm{m}}{\mathrm{s}^{2}}\right) \cdot\left(1 \frac{\mathrm{km}}{\mathrm{h}}=3.6 \frac{\mathrm{m}}{\mathrm{s}}\right)}{=} d=\frac{0.0039 v^{2}}{\mu}$

Where: 


$$
\begin{aligned}
& v=\text { Design Speed }(\mathrm{km} / \mathrm{h}) \\
& d=\text { Braking Distance }(\mathrm{m}) \\
& F_{k}=\text { Longitudinal Friction Force } \\
& N=\text { Normal Reaction Force } \\
& V=\text { Design Speed }(\mathrm{km} / \mathrm{h}) \\
& a=\text { Deceleration Rate }(\mathrm{m} / \mathrm{s} 2) \\
& m=\text { Mass of Vehicle }(\mathrm{Kg}) \\
& \mu=\text { Coefficient of Friction } \\
& g=\text { Gravitational acceleration }(\mathrm{m} / \mathrm{s} 2)
\end{aligned}
$$

\begin{tabular}{|c|c|c|c|c|c|c|}
\hline Description & Icy & Snowy & Rainy & Wet & Dry & $\begin{array}{c}\text { Year and Studied } \\
\text { References }\end{array}$ \\
\hline \multirow{4}{*}{$\begin{array}{l}\text { The study are presented maximum and } \\
\text { minimum values }\end{array}$} & $\mathrm{Max}=1.2326$ & $\operatorname{Max}=1.224$ & $\operatorname{Max}=1.093$ & $\mathrm{Max}=1.093$ & $\operatorname{Max}=1.0799$ & \\
\hline & $\operatorname{Min}=0.049991$ & $\operatorname{Min}=0.18735$ & $\operatorname{Min}=0.82985$ & Min $=0.8645$ & $\operatorname{Min}=0.96122$ & 2013 [9] \\
\hline & $\begin{array}{l}0.15 \\
0.19\end{array}$ & $\begin{array}{l}0.20 \\
0.24\end{array}$ & - & $\begin{array}{c}0.3 \\
0.44\end{array}$ & 0.45 & 2010 [10] \\
\hline & $0.25>$ & - & - & $>0.5$ & $>0.5$ & $2004[11]$ \\
\hline \multirow[t]{2}{*}{ Jones and Childers reported } & - & - & - & 0.4 & 0.7 & 2013 [12] \\
\hline & $\begin{array}{c}0.15-0.3 \\
\text { (Black ice) }\end{array}$ & & & $0.7-0.8$ & $0.8-1$ & $2001[13]$ \\
\hline $\begin{array}{l}\text { The study is carried out by the } \\
\text { coefficient of friction for icy to dry } \\
\text { conditions values of } 0.2 \text { to } 0.8 \text { to be } \\
\text { considered. }\end{array}$ & 0.2 & - & - & - & 0.8 & 2012 [14] \\
\hline $\begin{array}{c}\text { The friction coefficient values are } \\
\text { based on observed speeds of } 93 \text { to } 99 \\
(\mathrm{Km} / \mathrm{h})\end{array}$ & 0.16 & 0.27 & - & 0.8 & 0.93 & 1997 [15] \\
\hline $\begin{array}{c}\text { This study using simulation software } \\
\text { Adams / Car with five default values } \\
\text { of coefficient of friction are } \\
\text { considered. }\end{array}$ & 0.18 & 0.28 & 0.4 & 0.5 & 0.6 & 2015 [16] \\
\hline $\begin{array}{l}\text { Longitudinal friction coefficient is } \\
\text { suggested between } 0.15 \text { and } 0.5\end{array}$ & 0.15 & - & - & - & 0.5 & $2003[17]$ \\
\hline $\begin{array}{l}\text { This study using simulation software } \\
\text { Adams / Car with four } \\
\text { values of coefficient of friction (for } \\
\text { Dry Concrete Pavement } 1.1973 \text { has } \\
\text { been considered. }\end{array}$ & 0.05 & 0.1946 & - & - & 1.2801 & 2017 [18] \\
\hline $\begin{array}{l}\text { Simulations were carried out with } \\
\text { MATLAB/SIMULINK for different } \\
\text { initial velocities under various road } \\
\text { conditions and alignments }\end{array}$ & 0.2 & 0.35 & - & 0.5 & 0.7 & 2015 [19] \\
\hline
\end{tabular}

Equation 3 can be chosen according to friction coefficient value choices by designer in different road surface conditions caused by different weather conditions. Table 2 shows the research that directly gives friction coefficient based on road surface conditions. In some studies, [8] it also suggested different equations for calculating braking distance (Table 3) based on road surface conditions (without considering direct effect of friction coefficient).

Table 2. Studies on the coefficient of friction

Table 3. Stopping Distance in Jones \& Childers study [8]

\begin{tabular}{cccccc}
\hline & \multicolumn{4}{c}{ Different Formula's for S.D (Stopping Distance) } \\
\hline $\begin{array}{c}\text { Deferent Road } \\
\text { Condition }\end{array}$ & Dry Surface & Wet Surface & Slush & Soft, Loose Snow & Compacted Snow \\
\hline Formula & S.D= D & S.D=1.7 D & S.D=2D & S.D = 3D & S.D=4D \\
\hline
\end{tabular}


Conducted studies in Table 3, show that the values of friction coefficient range from 0.049 to 1.232. As it is determined in Table 3, different studies on a road surface condition suggest different friction coefficient values that many of them are based on field studies. In this study, by having different friction coefficient values for different types of vehicles and various types of simulations, according to previous studies based on Adams/car simulation different, suggested values were investigated and simulated. The results of this research can be used in the relationships of AASHTO Green Book which is related to the friction coefficient, parts of the road which has not got any longitudinal and terrain slopes, without any considerable roughness in the asphalt concrete road surface. For instance, stopping sight distance (SSD) in direct routes (without horizontal and vertical curves) (Equation 1) is one of them [3]. Figure 6 is a simplified Diagram of acting forces on the wheels of vehicle while moving. According to Figure 6, the value of friction coefficient $(\mu)$ is obtained by dividing horizontal forces to vertical forces that is mentioned as a simplified numerator and based on acting acceleration in AASHTO[6].

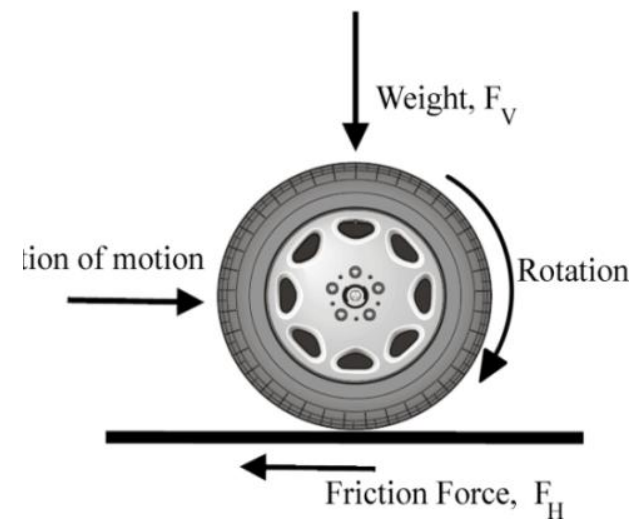

Figure 6. Simplified diagram of forces acting on a rotating wheel [6]

$\mu=\frac{F_{\text {Horizontal }}}{F_{\text {Vertical }}}=\frac{m a}{m g}=\frac{a}{9.81} \Rightarrow S S D=0.278 V t+\frac{V^{2}}{254\left(\frac{a}{9.81} \pm G\right)}$

By applying default conditions of the simulation $(\mathrm{G}=0 \%)$ on Equation 4, Equation 5 will be linear (AASHTO 2011):

$S S D=d_{B R}+d_{B}=0.278 V t+0.0039 \frac{V^{2}}{\frac{a}{10} \pm 0}=0.278 V t+0.039 \frac{V^{2}}{a}$

Where:

$S S D=$ Stopping Sight Distance $(\mathrm{m})$

$d_{B}=$ braking distance $(\mathrm{m})$

$d_{B R}=$ brake reaction distance $(\mathrm{m})$

$V=$ design speed $(\mathrm{km} / \mathrm{h})$

$a=$ deceleration rate $\left(\mathrm{m} / \mathrm{s}^{2}\right)$

Due to years of using both Equations 3 and 4 or 5 to calculate braking distance, Many major geometric design and road safety manuals have approved both equations (both braking distance equations are based on deceleration (a) and longitudinal coefficient of friction(f))[17].

\section{Methodology}

In order to analysis of vehicle-highway design interaction, using vehicle dynamic simulation modeling is inevitable, unless we should prepare a test track with all the vehicles, highway, and weather variables to make a lot of scenarios and measure all the responses of vehicles in various situations that is too much expensive and almost impossible. In this paper, the effect of friction coefficient changes due to the type of weather condition on the dynamic responses of three types of vehicle (Sedan, Bus, Truck) based on outputs of Adams/car simulation environment is investigated.

Since generally the type of vehicle and its features such as size (length, width and height), weight can be effective on friction coefficient, this research is done not only on Sedan, but on Bus and Truck for five different modes of friction coefficient and dynamic response of the vehicle. Simulation includes Braking which is known as a common driving behavior. 


\subsection{Simulation Process}

Adams/car simulation software is based on artificial intelligence which can perform tests on the dynamic response of vehicles in different highway designs. Moreover, is a module of the MSC Adams software package which can be used as the importance of the multi-body vehicle models is concerned. Although the number of errors in this simulator is high in delivering outputs, which increases the time of design and construction of the Roads, high accuracy and reliable results of its output values have still led to more use of it in the research.

This paper presented crucial details of simulation process with Adams/car, consequently Simulation menu of Adams/car Straight Line Events are used. Simulating to obtain dynamic responses of vehicle and full vehicle analysis in Four-Step is run as it following: (Figure 7).

Entering the vehicle model on Adams/car software (Open Assembly)

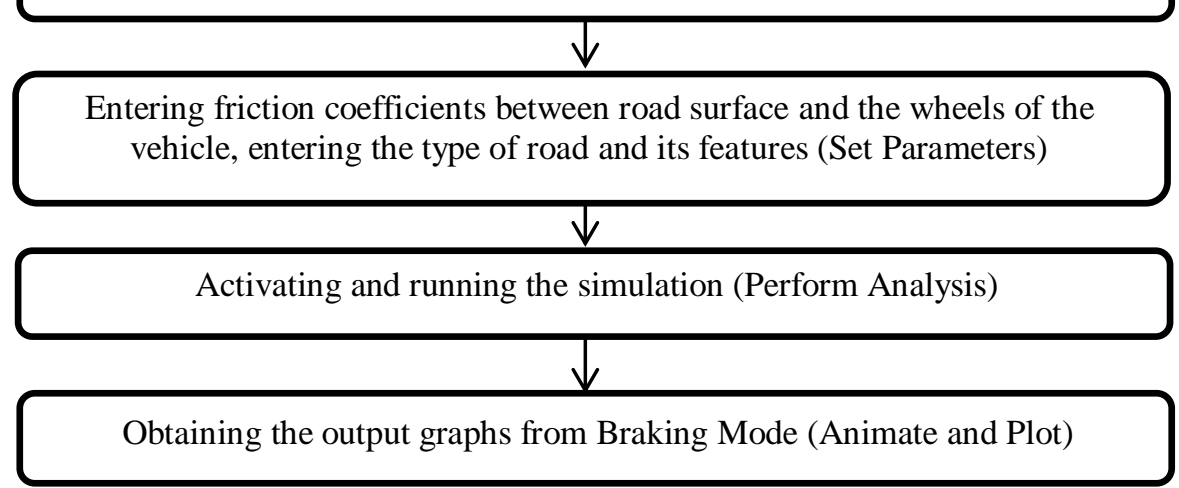

Figure 7. Four-Step Simulation in Adams/Car

\subsection{Selected Models of Vehicles}

Three types of vehicles which are selected are Sedan, Bus Rigid with Two Axle, Truck with three Axle in order to simulate (See Figure 8).
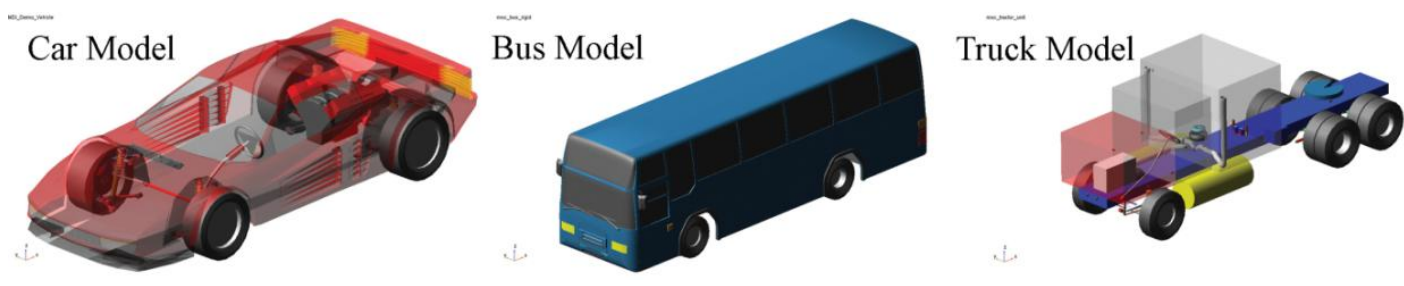

Figure 8. Vehicles' Model

The Sedan which is investigated [16] is lighter than Bus and Truck. Since friction coefficient is directly related to the weight force $(\mathrm{mg})$ and the mass of the vehicle, investigation on Bus and Truck is done based on weight. The vehicle includes bus which is rigid body and the Truck with three axles, single-axle front and rear tandem, also rear axle has four springs, and front has an Airbag-spring. Truck has six tensors (or moment of inertia at rest). Dynamic features of the mentioned vehicles are shown in Table 4.

Table 4. Dynamic features of the mentioned vehicles

\begin{tabular}{ccccccc}
\hline Vehicle Type & $\begin{array}{c}\text { Center of Mass Height } \\
(\mathbf{c m})\end{array}$ & $\begin{array}{c}\text { Mass } \\
(\mathbf{k g})\end{array}$ & $\begin{array}{c}\mathbf{I x x} \\
\left(\mathbf{k g} / \mathbf{m m}^{2}\right)\end{array}$ & $\begin{array}{c}\mathbf{I y y} \\
\left(\mathbf{k g} / \mathbf{m m}^{2}\right)\end{array}$ & $\begin{array}{c}\text { Length } \\
(\mathbf{c m})\end{array}$ & $\begin{array}{c}\text { Width } \\
(\mathbf{c m})\end{array}$ \\
\hline Sedan & 45 & 1527.68 & $2.0 \mathrm{E}+008$ & $5.0 \mathrm{E}+008$ & 400 & 200 \\
Rigid Bus & 97.4 & 11697.1 & $1.42 \mathrm{E}+010$ & $6.16 \mathrm{E}+011$ & 1050 & 260 \\
Truck Unit & 116.3 & 10844.3 & $4.27 \mathrm{E}+010$ & $3.79 \mathrm{E}+011$ & 850 & 250 \\
\hline
\end{tabular}




\subsection{Simulation Features}

Conducted tests are considered for Braking for 40 seconds and with the speed of 80 ( $\mathrm{km} \mathrm{per} \mathrm{h).} \mathrm{Start} \mathrm{of} \mathrm{Braking} \mathrm{is}$ the fifth second in each test with a deceleration of $0.34 \mathrm{~g}$ 's (according to [3]). Also for braking test in Adams/car, Close loop mode is used (See Figure 9).

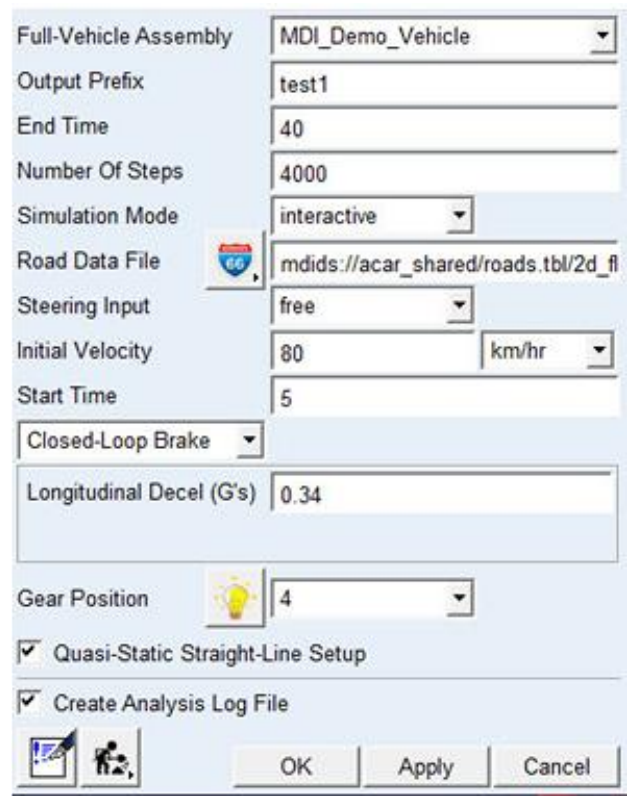

Figure 9. Braking test settings

\subsection{Reasons of Driving Behavior}

Two distinct modes of operation can be identified: free-rolling and full skidding. In free rolling mode (without any braking), there is not any relative speed between the pavement and the tire circumference. At full skidding, the circumferential tire speed is zero and the slip speed is equal to the speed of the vehicle. In typical braking conditions, the slip speed varies between these two extremes [6]. Figure 10 shows a portion of the simulation performed in the free steering mode of the sedan vehicle with 8 different friction coefficients.

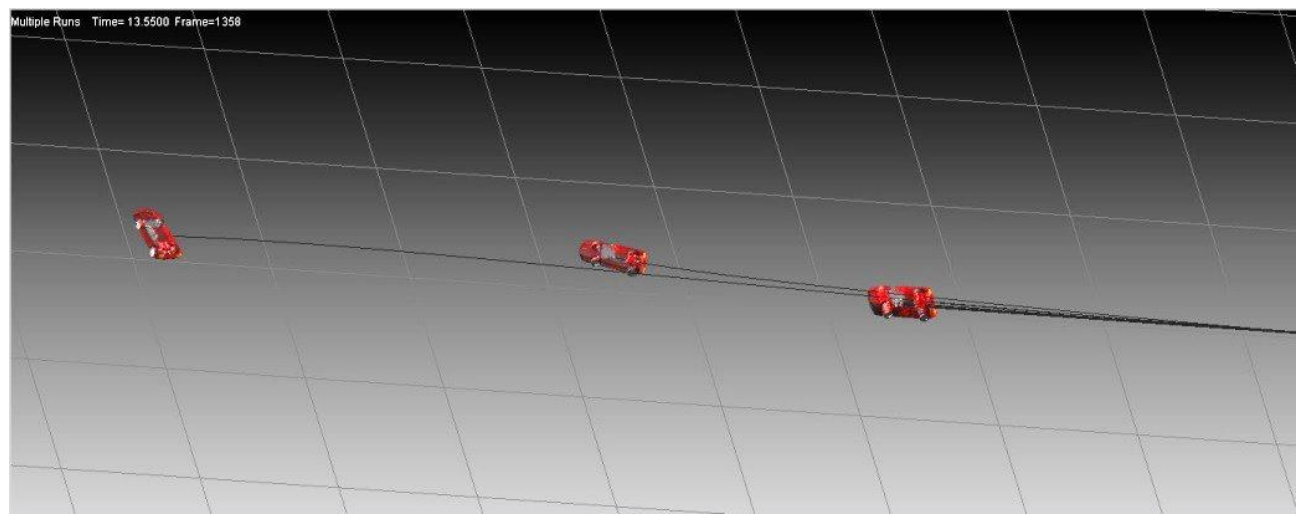

Figure10. Sedan Vehicle in Simulation test

As it can be observed in Adams/car:

In sliding movement of truck, there is a significant difference between two steering behavior (free steering and locked steering) is done by driver which is clearly shown in Figure 11. 


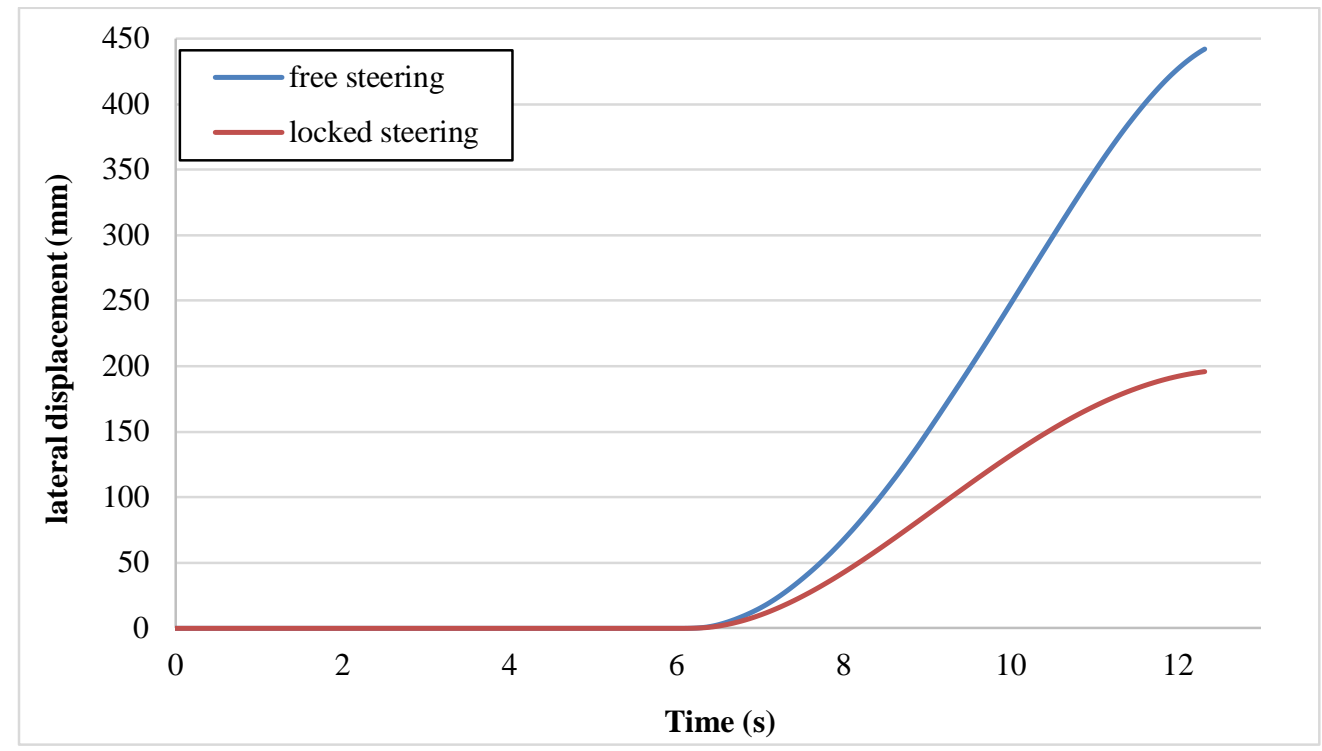

Figure 11. Difference Value between Locked and Free Steering (Speed $=80 \mathrm{Km} / \mathrm{h})$

\section{Results and Discussion}

4.1. The Analysis of Outputs and Investigating the Relationship between Friction Coefficient and the Length of Stopping Distance of Different Types of Vehicles in Free and Locked Steering

There are 48 tests altogether in order to obtain the values of Braking Distance, different values of 0.18, 0.28, 0.4, $0.5,0.6,0.7,0.8,0.9$ are entered in the simulation environment, and to define each of them to a specific weather condition and consequently a specific road condition, according to previous studies (Table 3), are named respectively for Icy, Snowy, Rainy, Wet, Dry, Dry-2, Dry-3. The outputs of Adams/car simulation environment for three types of vehicles of Sedan, Bus and truck in two different driving behavior modes of free and locked steering are obtained (Table 5).

Table 5. Braking Distance Based on Road Conditions for types of Vehicle (Speed $=80 \mathrm{Km} / \mathrm{h}$ )

\begin{tabular}{|c|c|c|c|c|c|c|c|c|}
\hline Road Surface Conditions & Icy & Snowy & Rainy & Wet & Dry & Dry1 & Dry2 & Dry3 \\
\hline$\mu$ (Coefficient Friction $)$ & 0.18 & 0.28 & 0.4 & 0.5 & 0.6 & 0.7 & 0.8 & 0.9 \\
\hline $\begin{array}{l}\text { Braking Distance } \\
\text { (Truck-Free) }(\mathrm{m})\end{array}$ & 307.6144 & 187.9897 & 85.6759 & 85.6064 & 85.6039 & 85.6025 & 85.6016 & 85.6010 \\
\hline $\begin{array}{l}\text { Braking Distance } \\
\text { (Truck-Locked) (m) }\end{array}$ & 307.5074 & 188.081 & 85.5267 & 85.485 & 85.4822 & 85.4806 & 85.4795 & 85.4785 \\
\hline $\begin{array}{l}\text { Braking Distance } \\
\text { (Bus-Free) }(\mathrm{m})\end{array}$ & 311.4074 & 169.5349 & 116.537 & 115.6078 & 115.4796 & 115.3656 & 115.3 & 114.6687 \\
\hline $\begin{array}{l}\text { Braking Distance } \\
\text { (Bus- Locked) }(\mathrm{m})\end{array}$ & 311.5601 & 162.1888 & 113.516 & 113.05 & 113.0428 & 113.0279 & 113.0146 & 113.007 \\
\hline $\begin{array}{l}\text { Braking Distance } \\
\text { (Sedan-Free) }(\mathrm{m})\end{array}$ & 178.424 & 132.886 & 112.902 & 107.02 & 104.591 & 104.319 & 104.319 & 104.11 \\
\hline $\begin{array}{c}\text { Braking Distance } \\
\text { (Sedan- Locked) (m) }\end{array}$ & 176.886 & 133.017 & 114.184 & 108.328 & 105.907 & 105.619 & 105.616 & 104.39 \\
\hline $\begin{array}{c}\text { Current AASHTO } \\
(2001,2004,2011)(\mathrm{m})\end{array}$ & - & - & - & - & - & - & - & - \\
\hline $\begin{array}{c}\text { Previous AASHTO } \\
(1940-1990)(\mathrm{m})(\text { Sedan })\end{array}$ & 138.666 & 89.1428 & 62.4 & 49.92 & 41.6 & 35.6571 & 31.2 & 27.733 \\
\hline $\begin{array}{l}\text { Jones \& Childers } \\
(2001)(\mathrm{m}) \text { (Sedan) }\end{array}$ & 166.4 & 124.8 & 83.2 & 70.72 & 41.6 & - & - & - \\
\hline
\end{tabular}

\subsection{Obtained Models from Simulation}

In order to calculate stopping distance for variety of roads, particularly those with high passing volume of heavy vehicles, the following models $(6,7,8,9,10,11)$ based on selected friction coefficient according to the dominant weather condition in the area of design, by selecting $0.9,0.8,0.7,0.6,0.5,0.4,0.28,0.18$ and putting them into the following models, the values which are really close to reality will be obtained. 


$$
\begin{aligned}
& B D_{\text {Truck }(\text { Free })}=872.25(\mu)^{2}-1179.3(\mu)+463.78, \quad R^{2}=0.9013 \\
& B D_{\text {Truck }(\text { Locked })}=872.49(\mu)^{2}-1179.6(\mu)+463.81, \quad R^{2}=0.9014 \\
& B D_{\text {Bus }(\text { Free })}=740.39(\mu)^{2}-988.3(\mu)+426.6, \quad R^{2}=0.8403 \\
& B D_{\text {Bus }(\text { Locked })}=750.63(\mu)^{2}-997.48(\mu)+425.37, \quad R^{2}=0.8254 \\
& B D_{\text {Sedan }(\text { Free })}=360.36(\mu)^{2}-452.72(\mu)+240.9, \quad R^{2}=0.9466 \\
& B D_{\text {Sedan }(\text { Locked })}=344.83(\mu)^{2}-433.73(\mu)+236.7, \quad R^{2}=0.9466
\end{aligned}
$$

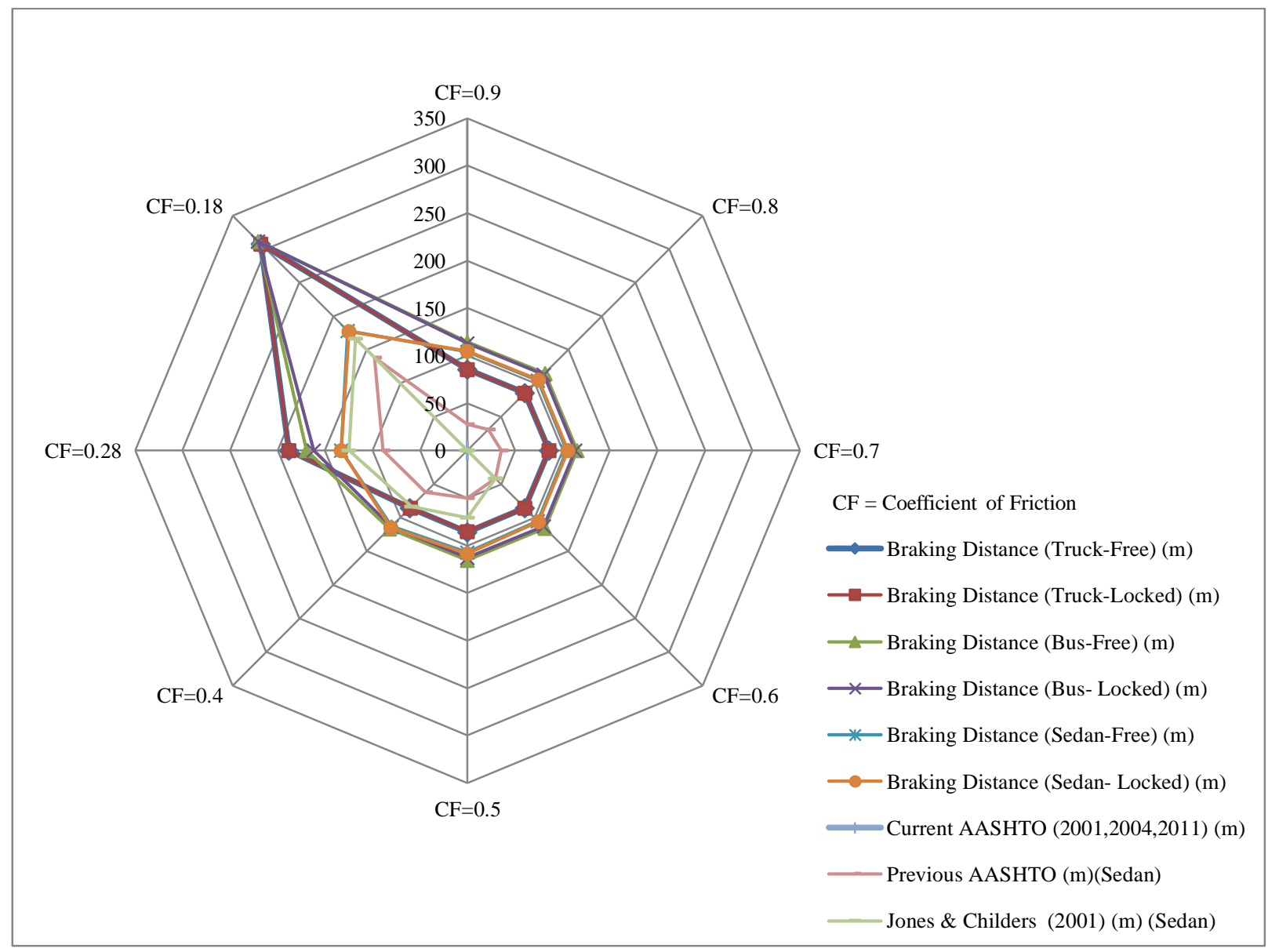

\begin{tabular}{|c|c|c|c|c|c|c|c|c|c|}
\hline \multirow{2}{*}{ Steering Mode } & \multirow{2}{*}{ Studies } & \multicolumn{8}{|c|}{$\mu$ (Friction Coefficient) } \\
\hline & & 0.18 & 0.28 & 0.4 & 0.5 & 0.6 & 0.7 & 0.8 & 0.9 \\
\hline \multirow{2}{*}{ Sedan (free) } & AASHTO & 22.28 & 32.9 & 44.73 & 53.84 & 60.22 & 65.8 & 70.09 & 73.36 \\
\hline & Jones\& Childers & 6.7 & 6.08 & 26.3 & 33.65 & 60.22 & - & - & - \\
\hline \multirow{2}{*}{ Sedan (locked) } & AASHTO & 21.6 & 33.01 & 45.35 & 53 & 60.72 & 66.2 & 70.46 & 73.43 \\
\hline & Jones\& Childers & 5.92 & 6.17 & 27.13 & 34.45 & 60.72 & - & - & - \\
\hline
\end{tabular}

Figure 12. Compare between ADAMS simulation, AASHTO and Jones \& Childers Study (Speed= $80 \mathrm{Km} / \mathrm{h}$ )

Because the most important studies on the values of the coefficient of friction in the longitudinal direction and its effect on braking distances is on the sedan vehicles, Table 6 for comparing the Values obtained from the simulation sedan vehicle than the values of AASHTO and Jones \& Childers (All values in percentage terms \& increased).

Table 6. Percentage difference once for Sedan in Free mode and once in locked mode (Speed= $80 \mathrm{Km} / \mathrm{h})$

According to models 6 to 11 , the corresponding equilibrium points are obtained with friction coefficients of 0.42 , $0.52,0.78$ (see Figure 13). At the equilibrium point of 0.42 , it was close to what was assumed in the simulation input 
for rainy weather conditions $(\mu=0.4)$, The difference between the braking distance of Sedan and Truck vehicles is almost zero. At the equilibrium point of 0.52 , close to what was assumed in the simulation input for wet conditions $(\mu$ $=0.5$ ), The braking distances for Sedan and Bus are approximately equal. At the equilibrium point of 0.78, among input values for simulation in dry weather conditions (Dry1 and Dry 2), the braking distance also equals to Sedan and Bus vehicles.

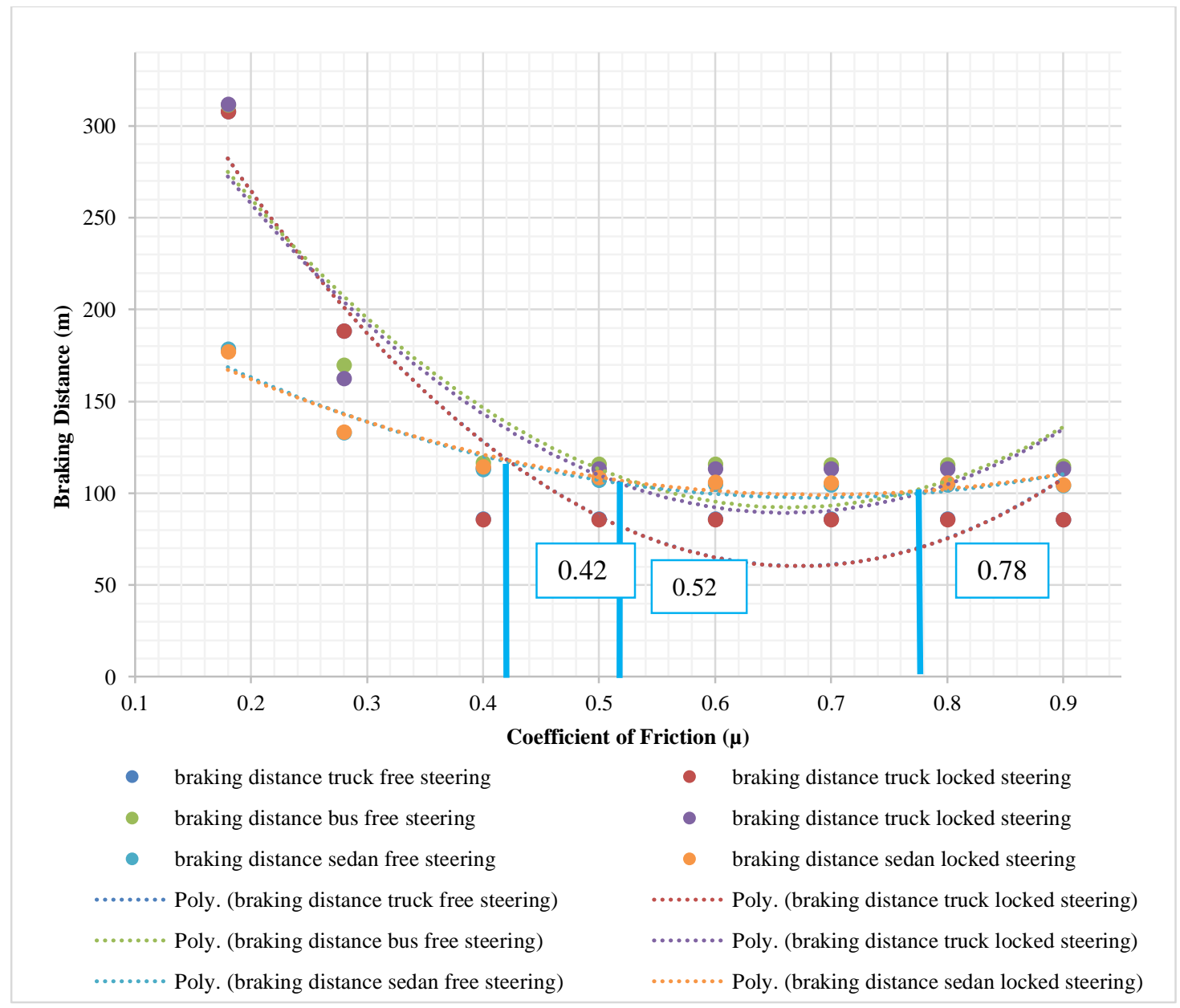

Figure 13. Obtained Curves from Simulation models

Examined values of the models represent that according to Literature Review (Table 2), the assumed friction coefficients for weather conditions are significant Values And can be considered as a friction coefficient with a precision in order to calculate the braking distance in the geometric design of road components in different road surface conditions.

Another result of this article is that the braking distance values are less than 0.4 (related to the road surface conditions in Rainy scenarios, see Figure 12) This suggests that with the changing road surface conditions on the rainy way $(\mu=0.4)$ to icy $(\mu=0.18)$, there is a lot of difference due to the weight and dynamic conditions of the heavy vehicles (BUS and Truck) than light vehicles (Sedan). For example, in a friction coefficient of 0.4 (Rainy), The difference in braking distance in a Locked Steering Truck Vehicle and is $25 \%$ greater than the Sedan's braking distance in locked steering. These value increase to $29.27 \%$ for the Snowy condition and $\mu=0.28$, and the friction coefficient of 0.28 (icy condition) reaches $42.47 \%$, which is a big difference.

\section{Conclusions}

In this paper conducted studies on different coefficient factors $(\mu)$ which every one of them is according to previous studies on different pavement surface conditions, are caused by different weather conditions. Since in Geometric design of roads coefficient friction is essential in designing elements, studies on stopping distance is done. In order to compare the result of this research to other related previous ones, the braking distance relationships of current AASHTO (2001, 2004 and 2011) and previous AASHTO (1994) and other studies are investigated. The results obtained from simulation based on Adams/car indicate that friction coefficients of 0.9, 0.8, 0.7and 0.6 do not have intensively significant differences in the values of braking distance and all of them can be attributed to dry weather condition. Although it was anticipated there were significant differences in braking distances in values of $0.5,0.4,0.28$ and 0.18 . Therefore $0.5,0.4,0.28$ and 0.18 can be allocated to wet, rainy, snowy and icy weather conditions 
respectively. For further clarification, the percentage differences are indicated in Table 6, this means that the percentage difference once for Sedan in Free mode and once in locked mode and also their comparisons to Jones \& Childers and AASHTO are stated. The mentioned values in previous AASHTO are considered in inputs of simulation due to considering coefficient friction, consequently braking distance are obtained. Also braking distances from simulation with Adams/car for Sedan, Bus and Truck in both modes of free and locked steering owing to the significant difference in lateral displacement and to investigate more precisely are obtained. The results obtained from the comparison of relationships of AASHTO, Jones \& Childers 2001 and simulation represent that the lowest vales of friction coefficient for geometric design belong to AASHTO, while Jones \& Childers suggest higher values, also the values of simulation suggest the highest values which there is no difference in free steering or locked mode.

\section{References}

[1] By US state .Icy road fatalities. (2008.2009.2010). "Icy Road Fatality Statistics" http://icyroadsafety.com/fatalitystats.shtml (June.26.2016) .

[2] US Dept. of Transportation (2005-2014). "Weather-Related Crash Statistics" <http://www.ops.fhwa.dot.gov/weather/q1_roadimpact.html> . (23 June, 2016).

[3] AASHTO (American Association of State Highway and Transportation officials. "A policy on geometric design of highways and streets, Washington", D.C. USA 20001). (2011).

[4] AASHTO (Association of State Highway and Transportation officials). "A policy on geometric design of highways and streets", Washington, D.C. USA. (1965).

[5] NCHRP400 (National Cooperative Highway Research Program Report). "Determination of Stopping Sight Distances". Transportation Research Board, Washington DC. (1997).

[6] NCHRP 108 (National Cooperative Highway Research Program Report). "Guide for Pavement Friction”. Transportation Research Board, (February 2009).

[7] Kordani, A.A., Molan, M.A. "The Effect of Combined Horizontal Curve and Longitudinal Grade on Side Friction Factors", KSCE Jour., 19(1), (2015): 303-310. DOI: 10.1007/s12205-013-0453-3.

[8] Univ. South Carolina. Contemporary College Physics. (2001), “The Friction of Automobile Tires". <http://boson.physics.sc.edu/ rjones/phys101/tirefriction.html>. (2 june 2002).

[9] Falero, V.J., "Development and evaluation of a virtual test environment for vehicle models with road friction estimator", thesis, Univ. Pontificia Comillas. Madrid. 2013, Pages 76-91.

[10] Hippi M, Juga I, Nurmi P. “A statistical forecast model for road surface friction.” InSIRWEC 15th International Road Weather Conference, Quebec City, Canada (February 2010): pp. 5-7.

[11] Siril Y, Askar K, Dougherty M. "Expert system to calculate the coefficient of friction-an approach to enhance traffic safety." InCybernetics and Intelligent Systems, 2004 IEEE Conference on 2004 Dec 1 (Vol. 2, pp. 803-808). IEEE. DOI:10.1109/ICCIS.2004.1460691.

[12] Mubarak W. Al-Grafi, Mostafa K. Mohamed, Farhan A. salem,“Analysis of Vehicle Friction Coefficient by Simulink/Matlab”. International Journal of Control, Automation and System. 2013 Jul; 2(2).

[13] Wallman, C.G., Åström, H.. Friction measurement methods and the correlation between road friction and traffic safety: A literature review, Statens väg-och transportforskningsinstitut (2001).

[14] Patra N, Datta K. Observer Based Road-Tire Friction Estimation for Slip Control of Braking System. Procedia Engineering [Internet]. Elsevier BV; 2012; 38:1566-74. DOI:10.1016/j.proeng.2012.06.192.

[15] Wallman, C.G., Wretling, P., Öberg, G. "Effects of Winter Road Maintenance", State-of-the-Art, Statens väg-och transportforskningsinstitut (1997).

[16] Tong C, Li T. "Car Driving Safety Analysis in Rainy and Snowy Weather Based on ADAMS/Car.” CICTP 2015, American Society of Civil Engineers; 2015 Jul 13. DOI:10.1061/9780784479292.266.

[17] PIARC (Permanent International Association of Road Congresses). "Road Safety Manual”,C13, (2003).

[18] You-Qun Zhao, Hai-Qing Li, Fen Lin, Jian Wang, Xue-Wu Ji. "Estimation of Road Friction Coefficient in Different Road Conditions Based on Vehicle Braking Dynamics. ” Chin. J. Mech. Eng. (May 2017):982-990. DOI 10.1007/s10033-017-0143-z.

[19] Yang JD, Chen YK, Shi Q, Li YM, Wang FC, Zhu L. Variable Speed Limits on Circular Curved Road Sections under Various Weather Conditions. InCICTP 20152015 Jul (pp. 3242-3253), DOI: org/10.1061/9780784479292.302. 